\title{
Surgical management and prognostic factors of spinal metastatic tumors
}

\author{
Wael A. A. Elmesallamy ${ }^{*}$ and Mahmoud M. Taha
}

\begin{abstract}
Objective: This study aims to evaluate different prognostic factors after surgical management of metastatic spinal tumors regarding clinical condition, preoperative investigations, histopathological results, and surgical data.

Methods: Seventy patients diagnosed as metastatic spinal tumors with neurological deficits and/or unstable spine operated for spinal decompression with or without instrumental fixation according to Spinal Instability Neoplastic Score (SINS) at our institute during the period from May 2014 to October 2018 with follow-up at least 9 months.

Results: Lymphoma metastases were the commonest spinal metastases of $23 \%$ with significant $p$ value $=0.001$, males and ages above 50 years old were significantly affected. High vascularity and bone invasion were significant operative findings. Significant good prognostic factors for both survival and Klekampe score improvement were paretic patients, $>15$ preoperative Klekampe score, early surgery, $\leq 3$ vertebral affection, extradural tumor location, gross total resection, and metastatic tumors from multiple myeloma, thyroid gland, lymphoma, and prostatic gland. Conclusion: Early surgeries aiming neural decompression and keeping spinal stability according to Spinal Instability Neoplastic Score for patients with spinal metastases are the main hope for better survival and neurological improvement.
\end{abstract}

Keywords: Spinal metastases, Spinal lymphoma, Decompression, Instrumental fixation

\section{Introduction}

Skeletal metastasis is second to lung and liver metastases. The most frequent area affected is the vertebral column. Spinal metastases estimate more than $10 \%$ of patients with tumors [1]. More than $80 \%$ of primary tumors were presented by metastases. The commonest primary tumors with bone metastases are prostate (84\%), breast (72\%), thyroid (50\%), kidney (37\%), pancreas (33\%), and lung (31\%) [2].

Extradural lesions either pure epidural or originating from the vertebra and extending to epidural space account for up to $95 \%$ of spinal metastatic lesions [3]. The thoracic spine is the commonest part involved. Intradural-extramedullary and intramedullary seeding account for $5-6 \%$ and $0.5-1 \%$ of spinal metastases,

\footnotetext{
* Correspondence: waelmesallamy@gmail.com

Neurosurgery Department, Faculty of Medicine, Zagazig University, Zagazig,
} Egypt

\section{Springer Open}

(c) The Author(s). 2020 Open Access This article is licensed under a Creative Commons Attribution 4.0 International License, which permits use, sharing, adaptation, distribution and reproduction in any medium or format, as long as you give appropriate credit to the original author(s) and the source, provide a link to the Creative Commons licence, and indicate if changes were made. The images or other third party material in this article are included in the article's Creative Commons licence, unless indicated otherwise in a credit line to the material. If material is not included in the article's Creative Commons licence and your intended use is not permitted by statutory regulation or exceeds the permitted use, you will need to obtain permission directly from the copyright holder. To view a copy of this licence, visit http://creativecommons.org/licenses/by/4.0/. poor [2].

Pain is the commonest symptom in $90 \%$ of patients [4]. Rapid progression is common in patients presented with neurological deficits [5].

MRI is the investigation of choice for spinal metastases [2]. Whole-body MRI is of high diagnostic accuracy for the detection of metastatic disease [6].

Metastatic tumors are the expression of a systemic disease and so require a team effort for decision-making; neurologic, oncologic, mechanical stability, and systemic treatment [7].

The indications of spinal metastases surgery are intractable pain, the onset of neurological deficit, and instability of the spine [8].

Prognostic factors of spinal metastases are status before and after treatment, age, sex, primary neoplasm pathology, and proper treatment selection [9]. 
Table 1 Neurological scoring system for neurological deficit assessment (Klekamp et al. [11])

\begin{tabular}{lllll}
\hline Score & Sensory disturbance & Motor weakness & Gait & Sphincter function \\
\hline 5 & No symptom & Full power & Normal & Normal \\
4 & Present, not significant & Movement against resistance & Unsteady, no aid & Slight disturbance, no catheter \\
3 & Significant, function not restricted & Movement against gravity & Mobile with aid & Residual, no catheter \\
2 & Some restriction of function & Movement without gravity & Few steps with aid & Rarely incontinent \\
1 & Severe restriction of function & Contraction without movement & Standing with aid & Often catheter \\
0 & Incapacitated function & Plegia & Plegia & Permanent catheter \\
\hline
\end{tabular}

The aim of this study is to evaluate the prognostic factors of patients with spinal metastasis.

\section{Patients and methods}

Seventy patients with spinal metastatic tumors were operated at the Neurosurgery Departement, Zagazig University Hospital, from May 2014 to October 2018 after approval from the local ethical committee and Zagazig University Institutional Review Board (Zu-IRB). Informed consent according to the criteria set by the local research ethics committee in our center were obtained in writing before surgery of the patients. Data collected were from clinical records, preoperative investigations, surgical data, and postoperative follow-up for evaluation of the prognostic factors of this disease.

All patients subjected for evaluation of the general and neurological conditions besides laboratory, radiological, and imaging investigation before surgery for detection of primary tumors, other metastases, and fitness for surgery. Patients who were fit for surgery operated for spinal decompression, tumor resection, and instrumental fixation when indicated according to Spinal Instability Neoplastic Score (SINS) [10]. Intraoperative imaging by X-ray and or ultrasound may be used. MRI spine was done during the first $48 \mathrm{~h}$ after surgery for assessing the extent of resection. Gross total resection (GTR) considered when no visible mass in postoperative imaging, subtotal resection (STR) when > 50\% resection, and partial (p) resection when less 50\% resection. All patients were followed up till hospital discharge and at least for 9 months postoperatively by clinical assessment and MRI spine. Klekampe et al. [11] score (Table 1) was used to assess the condition

Table 2 Demographic data

\begin{tabular}{llll}
\hline Parameters & No & $\%$ & $p$ \\
\hline Sex & & & \\
$\quad$ Male & 44 & 63 & 0.03 \\
$\quad$ Female & 26 & 37 & \\
Age & & & 0.01 \\
$27-50$ years & 18 & 26 & \\
$>50$ years & 52 & 74 & \\
\hline
\end{tabular}

of the patients preoperatively and during follow-up. Klekampe improvement rate (Klekampe rating) =

[( postoperative Klekampe score - preoperative Klekampe score)/(20 - preoperative Klekampe score)]-100 was used to measure the degree of improvement.

The patients had been sent after surgery for radiotherapy and chemotherapy management. Patients included in this study were diagnosed as metastatic spinal tumors and fit for surgery under general anesthesia with neurological deficits or unstable spine. Patients without definite pathological diagnosis and other organ metastasis were excluded from this study. Thirty-six patients were diagnosed before spinal manifestations as known primary cancer elsewhere. All patients received postoperative radiotherapy and chemotherapy.

Data collected, analyzed, and submitted to statistical analysis using statistical packages for social science (SPSS) version 20. $p$ value was set to $<0.05$ for significant results.

\section{Results}

This study included 70 patients; 44 males and 26 females $($ male to female ratio $=1.7: 1)$ with ages ranged from 27 to 73 years old. Spinal metastases significantly affecting

Table 3 Neurological presentation

\begin{tabular}{|c|c|c|c|}
\hline Parameters & No & $\%$ & $p$ \\
\hline Back pain & 70 & 100 & \\
\hline Motor affection & 50 & 71 & 0.01 \\
\hline Paresis & 38 & 54 & \\
\hline Plegic & 12 & 17 & \\
\hline Sensory affection & 54 & 77 & 0.01 \\
\hline Sphincter affection & 32 & 46 & 0.1 \\
\hline Duration of symptoms & & & 0.07 \\
\hline$<1$ week & 24 & 34 & \\
\hline 1 week to 1 month & 26 & 37 & \\
\hline$>1$ month & 20 & 29 & \\
\hline Preoperative Klekampe score & & & 0.02 \\
\hline $15-19 / 20$ & 26 & 37 & \\
\hline $10-14 / 20$ & 12 & 17 & \\
\hline $0-9 / 20$ & 32 & 46 & \\
\hline
\end{tabular}


Table 4 Spine affection

\begin{tabular}{llll}
\hline Parameters & No & $\%$ & $p$ \\
\hline Level & & & \\
$\quad$ Cervical and cervicodorsal junction & 12 & 17 & \\
Dorsal & 40 & 57 & 0.001 \\
Lumber & 10 & 14 & \\
$\quad$ Dorsolumber & 8 & 11 & \\
Extension & & & \\
One vertebra & 16 & 23 & \\
2-3 vertebrae & 44 & 63 & 0.001 \\
$>3$ vertebrae & 10 & 14 & \\
Location to dura & & & \\
Extradural & 62 & 88.6 & \\
Intramedullary & 2 & 2.9 & 0.0001 \\
Intradural-extramedullary & 6 & 8.6 & \\
Bone collapse & 40 & 57 & \\
\hline
\end{tabular}

male patients $(p=0.03)$ and ages above 50 years old $(p$ $=0.01$ ) (Table 2). All patients suffered back pain (100\%), and the main neurological manifestations were motor power affections in 50 patients (71\%); of them, 12 patients were plegics and 38 were paretics; sensory affection as a sign was detected in 54 patients (77\%), and sphincteric affections were symptomized in 32 patients (46\%). Four patients suffered rapid progression of neurological condition within $24 \mathrm{~h}$ from first symptom to complete loss of functions. Sensory affection and/or back pain were the initial manifestations in this study. The duration of symptoms ranged from 2 days to 14 weeks before spinal surgery (Table 3 ). Table 4 showed statistically significant dorsal spine affection $(p=0.001)$, $2-3$ vertebral extension $(p=0.001)$, and extradural location of metastatic tumors $(p=0.0001)$. High vascularity and bone invasion were statistically significant surgical findings. Gross total resections were achieved in only $16 / 70(23 \%)$ patients while partial resections were achieved in 30 patients (42\%) with significant $p=0.03$, and instrumental spinal fixations were done in $54 \%$

Table 5 Surgical data

\begin{tabular}{llll}
\hline Parameters & No & $\%$ & $p$ \\
\hline Resection & 16 & 23 & \\
Gross total & 24 & 34 & 0.03 \\
Subtotal & 30 & 42 & \\
Partial & 38 & 54 & 0.05 \\
Instrumentation & 44 & 63 & 0.01 \\
High vascularity & 54 & 77 & 0.001 \\
Bone invasion & & &
\end{tabular}

Table 6 Postoperative complication

\begin{tabular}{lll}
\hline Parameters & No & $\%$ \\
\hline Wound infection & 6 & 9 \\
CSF leak & 4 & 6
\end{tabular}

patients according to Spinal Instability Neoplastic Score (SINS) [10] (Table 5). All postoperative complications were managed by conservative treatment as 6 patients (9\%) suffered wound infections and 4 patients (6\%) suffered cerebrospinal fluid leak (Table 6). Table 7 represented the histopathological results of spinal metastases in this study, and lymphoma was the commonest type in $16 / 70(23 \%)$ patients with significant $p$ value $=0.001$. Table 8 represented the outcome as we measured by Klekampe score improvement (Klekampe score improvement after 9 months from surgery) and survival of the patients after 9 months from surgery. We found Klekampe score improvement after 9 months from surgery in $44 / 70(63 \%)$ patients with statistically significant ( $p<$ 0.05) good prognostic factors for Klekampe score improvement; paretic patients, > 15 preoperative Klekampe score, early surgery $<1$ week duration of spinal symptoms, $\leq 3$ vertebral affection, extradural tumor location, gross total or subtotal resection, $>1$ year duration between primary tumor diagnosis and spinal metastases diagnosis, and metastatic tumors from multiple myeloma, thyroid gland, lymphoma, or prostatic gland. We found the survival after 9 months from surgery 58/ $70(83 \%)$ patients with statistically significant $\left(p^{*}<0.05\right)$ good prognostic factors for survival; paretic patients, > 15 preoperative Klekampe score, early surgery till 1 month duration of spinal symptoms, one vertebral affection, lumber affection, extradural or intraduralextramedullary tumor location, gross total resection, and metastatic tumors from multiple myeloma, thyroid gland, lung, or prostatic gland. Table 9 represented the clinical status of the patients after 9 months from

Table 7 Histopathology

\begin{tabular}{lllr}
\hline Parameters & No & $\%$ & $p$ \\
\hline Lymphoma & 16 & 23 & 0.01 \\
Hepatocellular carcinoma & 10 & 14 & \\
Thyroid carcinoma & 8 & 11 & \\
Breast carcinoma & 8 & 11 & \\
Prostatic carcinoma & 8 & 11 & \\
Cancer bladder & 6 & 9 & \\
Lung carcinoma & 4 & 6 & \\
Nasopharyngeal carcinoma & 4 & 6 & \\
Multiple myelomas & 4 & 6 & \\
Ependymoma & 2 & 3 & \\
\hline
\end{tabular}


Table 8 Ninth month postoperative outcome (Klekampe score improvement and survival)

\begin{tabular}{|c|c|c|c|c|c|c|}
\hline & \multicolumn{3}{|c|}{$\begin{array}{l}\text { Klekampe score } \\
\text { improvement }\end{array}$} & \multicolumn{3}{|c|}{ Survival } \\
\hline & No & $\%$ & $p$ & No & $\%$ & $p^{*}$ \\
\hline Age & & & 0.05 & & & 0.07 \\
\hline$\leq 50$ years & $10 / 18$ & 56 & & $16 / 18$ & 89 & \\
\hline$>50$ years & $34 / 52$ & 65 & & $42 / 52$ & 81 & \\
\hline Sex & & & 0.05 & & & 0.05 \\
\hline Male & $26 / 44$ & 58 & & $38 / 44$ & 86 & \\
\hline Female & $18 / 26$ & 69 & & $20 / 26$ & 77 & \\
\hline Clinical & & & 0.001 & & & 0.01 \\
\hline Back pain & $40 / 70$ & 57 & & $58 / 70$ & 83 & \\
\hline Paresis & $28 / 38$ & 74 & & $34 / 38$ & 89 & \\
\hline Plegia & $2 / 12$ & 17 & & $4 / 12$ & 33 & \\
\hline Sensory & $36 / 52$ & 67 & & $40 / 52$ & 77 & \\
\hline Sphincter & $8 / 32$ & 25 & & $20 / 32$ & 63 & \\
\hline Duration before surgery & & & 0.001 & & & 0.03 \\
\hline$<1$ week duration & $20 / 24$ & 83 & & $22 / 24$ & 92 & \\
\hline$>1$ week-1 month & $16 / 26$ & 62 & & $24 / 26$ & 92 & \\
\hline$>1$ month duration & $8 / 20$ & 40 & & $12 / 20$ & 60 & \\
\hline Preoperative Klekampe score & & & 0.001 & & & 0.03 \\
\hline $15-19 / 20$ & $24 / 26$ & 92 & & $26 / 26$ & 100 & \\
\hline $10-14 / 20$ & $9 / 12$ & 75 & & $10 / 12$ & 83 & \\
\hline $0-9 / 20$ & $11 / 32$ & 34 & & $22 / 32$ & 69 & \\
\hline Level & & & 0.05 & & & 0.01 \\
\hline $\begin{array}{l}\text { Cervical and cervicodorsal } \\
\text { junction }\end{array}$ & $8 / 12$ & 67 & & $8 / 12$ & 67 & \\
\hline Dorsal & $26 / 40$ & 65 & & $36 / 40$ & 90 & \\
\hline Lumbar & $6 / 10$ & 60 & & $10 / 10$ & 100 & \\
\hline Dorsolumber & $4 / 8$ & 50 & & $4 / 8$ & 50 & \\
\hline Extension & & & 0.01 & & & 0.01 \\
\hline One vertebra & $10 / 16$ & 63 & & $16 / 16$ & 100 & \\
\hline $2-3$ vertebrae & $32 / 44$ & 73 & & $36 / 44$ & 82 & \\
\hline$>3$ vertebrae & $2 / 10$ & 20 & & $6 / 10$ & 60 & \\
\hline Location to dura & & & 0.01 & & & 0.01 \\
\hline Extradural & $41 / 62$ & 66 & & $52 / 62$ & 84 & \\
\hline Intramedullary & $1 / 2$ & 50 & & $1 / 2$ & 50 & \\
\hline Intradural-extramedullary & $2 / 6$ & 33 & & $5 / 6$ & 84 & \\
\hline Resection & & & 0.02 & & & 0.02 \\
\hline Gross total & $12 / 16$ & 75 & & $16 / 16$ & 100 & \\
\hline Subtotal & $18 / 24$ & 75 & & $20 / 24$ & 83 & \\
\hline Partial & $14 / 30$ & 47 & & $22 / 30$ & 73 & \\
\hline Instrumentation & & & 0.6 & & & 0.05 \\
\hline Yes & $24 / 38$ & 63 & & $34 / 38$ & 89 & \\
\hline No & $20 / 32$ & 63 & & $24 / 32$ & 75 & \\
\hline Duration between & & & 0.01 & & & 0.07 \\
\hline
\end{tabular}

Table 8 Ninth month postoperative outcome (Klekampe score improvement and survival) (Continued)

\begin{tabular}{|c|c|c|c|c|c|c|}
\hline & \multicolumn{3}{|c|}{$\begin{array}{l}\text { Klekampe score } \\
\text { improvement }\end{array}$} & \multicolumn{3}{|c|}{ Survival } \\
\hline & No & $\%$ & $p$ & No & $\%$ & $p^{*}$ \\
\hline \multicolumn{7}{|l|}{$\begin{array}{l}\text { primary tumor and } \\
\text { spinal metastasis diagnosis }\end{array}$} \\
\hline \multicolumn{7}{|l|}{$n=36$} \\
\hline$\leq 1$ year & $16 / 24$ & 66.7 & & $22 / 24$ & 92 & \\
\hline$>1$ year & $12 / 12$ & 100 & & $12 / 12$ & 100 & \\
\hline Histopathology & & & 0.03 & & & 0.001 \\
\hline Lymphoma & $12 / 16$ & 75 & & $14 / 16$ & 88 & \\
\hline Hepatocellular carcinoma & $4 / 10$ & 40 & & $6 / 10$ & 60 & \\
\hline Thyroid carcinoma & $6 / 8$ & 75 & & $8 / 8$ & 100 & \\
\hline Breast carcinoma & $4 / 8$ & 50 & & $6 / 8$ & 75 & \\
\hline Prostatic carcinoma & $6 / 8$ & 75 & & $8 / 8$ & 100 & \\
\hline Cancer bladder & $4 / 6$ & 66.7 & & $5 / 6$ & 83 & \\
\hline Lung carcinoma & $1 / 4$ & 25 & & $4 / 4$ & 100 & \\
\hline Nasopharyngeal carcinoma & $2 / 4$ & 50 & & $2 / 4$ & 50 & \\
\hline Multiple myelomas & $4 / 4$ & 100 & & $4 / 4$ & 100 & \\
\hline Ependymoma & $1 / 2$ & 50 & & $1 / 2$ & 50 & \\
\hline
\end{tabular}

surgery, and we found statistically significant $>15$ Klekampe score in 29/58(50\%) survived patients as $p=$ 0.001 while before surgery $0-9$ Klekampe score was significant in $32 / 70(46 \%)$ patients as $p=0.02$. The degree of Klekampe score improvement after 9 months from surgery was calculated by the equation Klekampe improvement rate (Klekampe rating $)=[($ postoperative Klekampe score - preoperative Klekampe score)/(20 preoperative Klekampe score)] $\times 100$; we found $>50 \%$ improvement rating in 26/44(59\%) of improved patient which was statistically significant as $p=0.01$.

\section{Discussion}

This study was conducted on 70 cases with spinal metastases; 44 males and 26 females. Ages ranged from 27 to 72 years old. Male sex and old ages more than 50 years

Table 9 Ninth month Klekampe score and rating

\begin{tabular}{llll}
\hline Parameters & No & $\%$ & $p$ \\
\hline Postoperative Klekampe score (ninth month) & & & 0.001 \\
$15-19 / 20$ & $29 / 58$ & 50 & \\
$10-14 / 20$ & $12 / 58$ & 21 & \\
$0-9 / 20$ & $17 / 58$ & 29 & \\
Klekampe score improvement rate (ninth month) & $6 / 44$ & 14 & 0.001 \\
$\leq 25 \%$ & & & \\
$>25 \leq 50$ & $12 / 44$ & 27 & \\
$>50$ & $26 / 44$ & 59 & \\
\hline
\end{tabular}




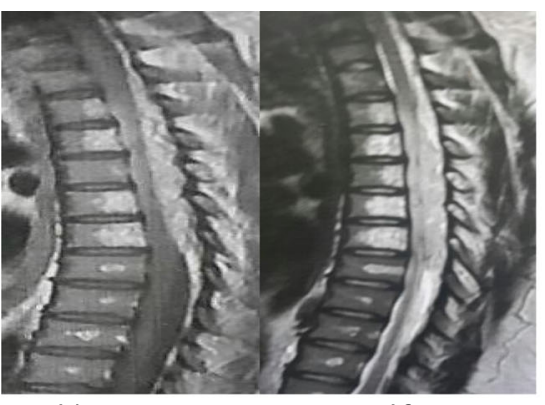

A1

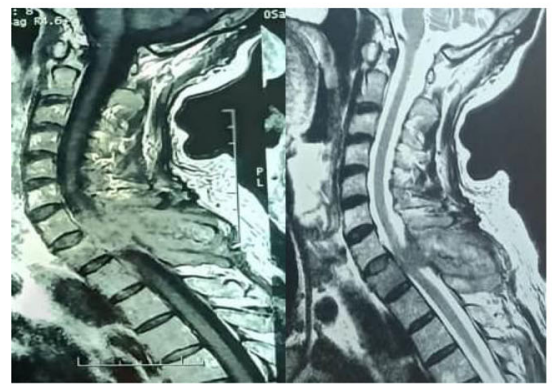

C1

E1
C2

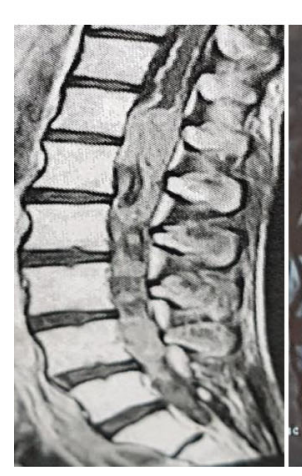

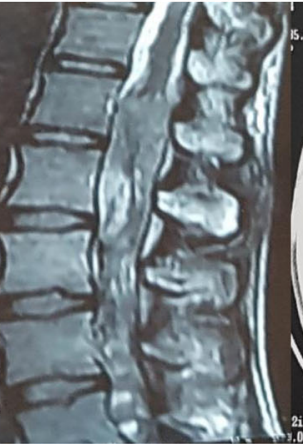

E2

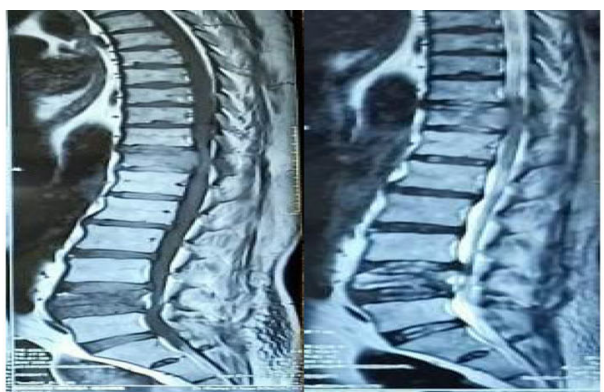

B2

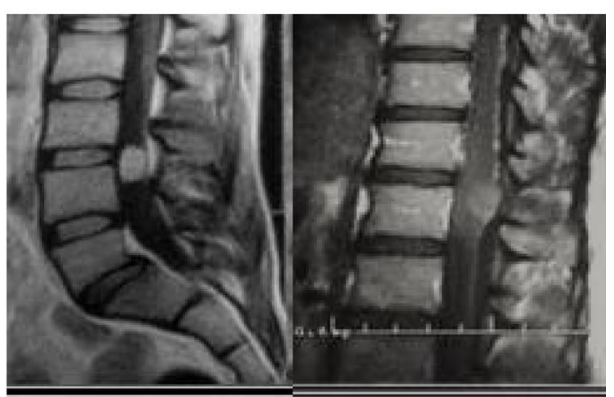

D1

D2

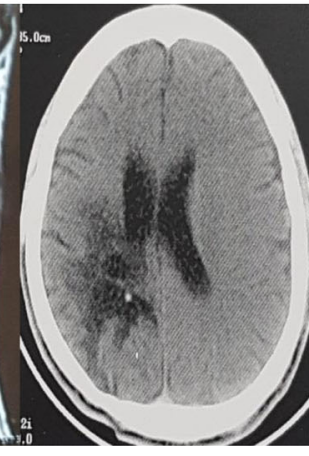

E3

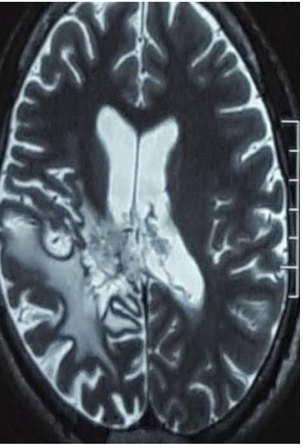

E4

Fig. 1 Sagittal MRI spine with contrast showing different spinal metastatic locations and types. A1, A2 Dorsal spine extradural lymphoma metastases. B1, B2 Dorsolumber spine extradural prostatic metastases. C1, C2 Cervical spine extradural metastatic hepatoma. D1, D2 Dorsolumber spine intradural-extramedullary multiple myeloma of the same patient. E1, E2 Dorsolumber spine intradural and intramedullary metastatic ependymoma. E3, E4 CT and MRI brain of the same patient who operated 4 years before spinal metastases for brain ependymoma

old were statistically significantly affected. Sciubba et al. [12] found a high incidence of metastatic spinal tumors in males and ages 40-65 years old, probably due to the high incidence of prostatic cancer to affect bone and higher prevalence of lung malignancy in these groups. Old ages and male sex prevalence for metastatic spinal were documented in many studies [13-15].

Low back pain was presented by all patients at diagnosis, and sensory affection was found in 77\%, motor affection in $71 \%$, and sphincteric affection in $46 \%$. Four patients suffered rapid progression of the neurological condition within $24 \mathrm{~h}$ from the first symptom to complete loss of functions. Sensory affection and/or back pain was the initial manifestations in this study.
Helweg et al. [16] showed that the commonest symptom was pain, which may be nocturnal and local or radiating. Sensory affection is the first in early neural tissue compression followed by motor deficits then sphincteric affection. Pain presented in $90 \%$, motor disturbance in $85 \%$, and sphincter disturbance in $37 \%$. Similar and nearly the same scenario of clinical manifestations described in many studies on spinal metastases with little changes in percentages as different sample sizes and cultures of areas in which the researches had been done $[14,17,18]$. Pain is worse at night and during recumbency as lengthening of the spine and distension of the epidural venous plexus [19]. In this study, the shortest duration of neurological deficits before surgery was 2 


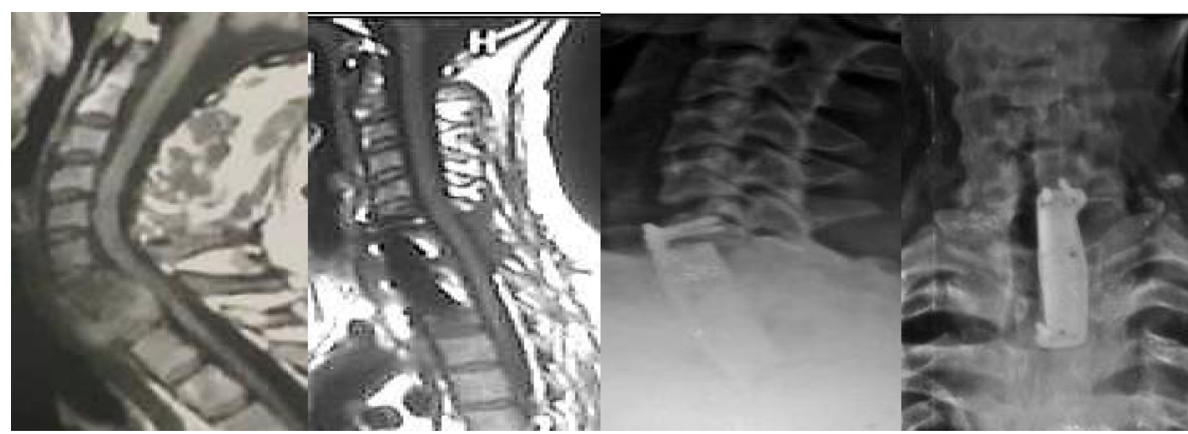

A

B

C1

$\mathrm{C} 2$

Fig. 2 Case of spinal nasopharyngeal carcinoma metastases. A Preoperative T1 MRI with a contrast of cervicodorsal spine nasopharyngeal carcinoma metastases. B Postoperative T1 MRI with contrast. C1, C2 Postoperative plain X-ray showing C6-T2 instrumental reconstruction

days and the longest was 14 weeks. Ninety percent of Lei et al. [20] patients suffered 2-6 weeks before surgeries. In our study, dorsal spines, $2-3$ vertebrae, and extradural space were significantly more affected. Dorsal spine metastatic location reported by many research to be the commonest as [14, 21-23], but Tatsui et al. [24] found from 695 patients, 15\% cervical location, 29.2\% dorsal, and $55.5 \%$ lumber location. The predilection for the thoracic spine is due to the number, vascular supply, and nearby organs [25].

In this study, postoperative complications were wound infection in 6 cases $(9 \%)$ and cerebrospinal fluid leakage in 4 cases (6\%). Brazilia et al. [26] concluded that durable control of metastatic spinal tumors can be achieved with limited complications.

Our results showed significant improvement after 9 months from surgery in patients with paresis or sensory deficits than those with plegia or sphincteric affection, also significant improvement with short duration of complaints less than 1 week before surgery, high preoperative Klekampe score, $>1$ year duration between primary tumor and spinal metastasis diagnosis, $\leq 3$ vertebrae affection, extradural location, and surgical resection either total or subtotal.

Early diagnosis and treatment especially as the patient is still ambulatory is important for recovery and longer survival. Even when the diagnosis is made late but remained some spinal function, surgery may lead to better functional outcomes. The prognosis depends on the duration and severity of preoperative deficits [16, 20, 27]. Rades et al. [28] found a statistically significant improvement in patients with a high Klekampe score (15-20/20). The interval between the diagnosis of primary malignancy and spinal metastasis affects the prognosis as low speed of dissemination will tend to have long survival after treatment [16].

Histopathology of the tumor plays a big role in the outcome as determine responsiveness to adjuvant radiotherapy and chemotherapy [29]. Major organ metastasis is a significant factor for survival [30]. In our study, multiple myeloma, lymphoma, thyroid carcinoma, and prostatic carcinoma showed significantly better prognosis than lung cancers and hepatocellular carcinoma. Bacci et al. [29] reported that hematological malignancies and breast carcinoma are sensitive to adjuvant treatment while non-small

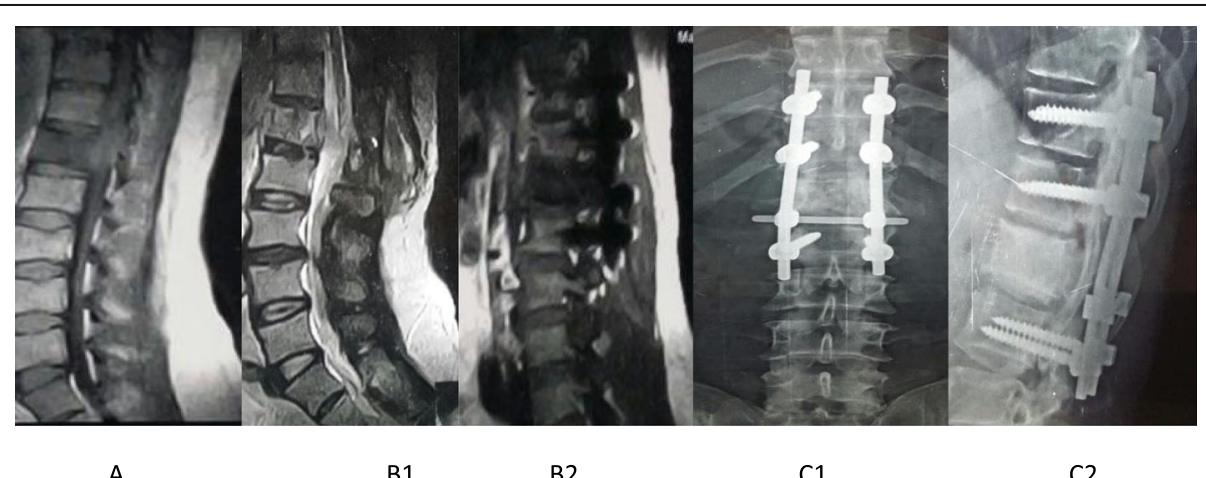

A

B1

B2

C1

C2

Fig. 3 Case of spinal cancer bladder metastases. A Preoperative T1 MRI with contrast of lumber spine cancer bladder metastases. B1 Central sagittal postoperative MRI. B2 Peripheral sagittal postoperative MRI. C1, C2 Postoperative plain X-ray showing instrumental reconstruction 


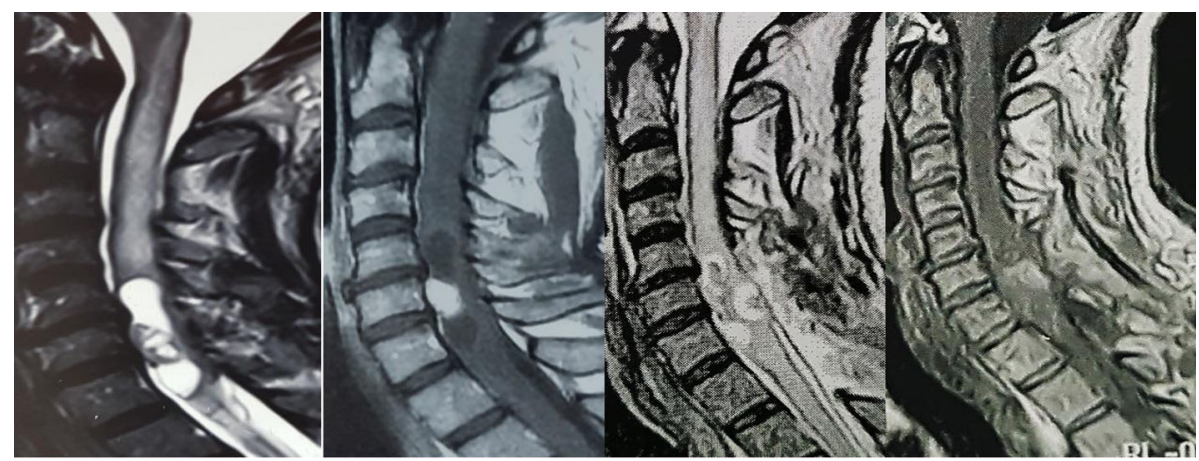

A1

A2

B1

B2

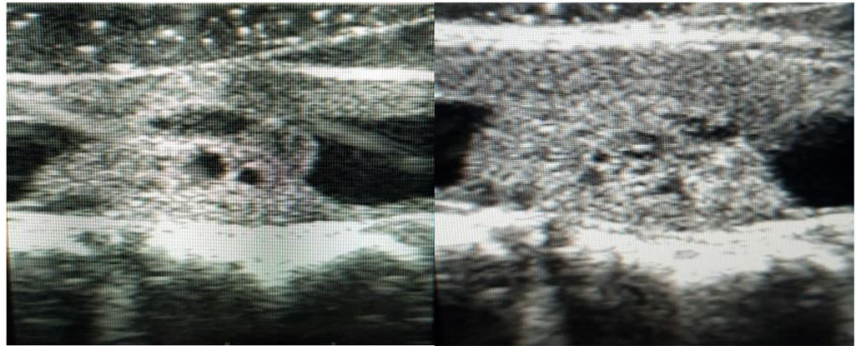

C1

C2

Fig. 4 Case of spinal metastatic ependymoma. A1, A2 Preoperative MRI T2 and T1 cervical spine with intramedullary metastatic ependymoma. B1, B2 Postoperative MRI T2 and T1. C1, C2 Intraoperative ultrasound images showing hypoechoic cystic parts and hyperechoic fleshy tumor parts

cell lung carcinoma is moderately radioresistant. Sioutos et al. [15] found the better survival was with renal, breast, and prostatic spinal metastasis. Chang et al. [23] reported that the highest 1-year survival was with spinal breast cancer and the lowest was with lung cancers.

After 9 months from surgery, we found that age and sex of the patients, metastatic spine levels, and instrumental fixation during surgery did not have a significant influence on prognosis. Hirabayashi et al. [31] reported sex and age did not affect the outcome. Spinazze et al. [32] documented that patients' age does not affect improvement. Klekamp et al. [33] found no difference between upper and lower spine affection, while Atanasiu et al. [34] reported that upper cervical affection had adverse effects on life with an average survival of 1.8 months.

In this study, we faced different spinal metastases in locations and pathologies for which we used different surgical modalities for resection either anterior or posterior approaches with or without instrumental stabilization (Figs. $1,2,3$, and 4).

\section{Conclusion}

Spinal metastatic tumors are systematic diseases. The goal of treatment is to relieve pain, stabilize the spinal structure, and maintain neurologic function. Timely diagnosis and appropriate treatment selection are vital in optimizing the outcomes of treatment of metastatic spinal disease; this was achieved by advances in diagnostic tools, spine surgeries, and adjuvant therapies. Early surgeries aiming neural decompression and keeping spinal stability according to Spinal Instability Neoplastic Score for patients with spinal metastases are the main hope for better survival and neurological improvement.

\section{Acknowledgements}

The authors are lucky to work with the neurosurgery team at Zagazig University Hospital for their great help and support.

\section{Authors' contributions}

WE and MT contributed to the study conception, design, most surgical works, data collection, and drafting of the manuscript. Both authors read and approved the final manuscript.

\section{Funding}

All patients were operated at the Neurosurgery Department, Zagazig University Hospital, for free.

\section{Availability of data and materials}

All data that support the findings of this study are available from the Neurosurgery Department, Zagazig University Hospital. Data are however available from the author when requested with permission.

\section{Ethics approval and consent to participate}

A research committee approval has been granted for this study by the medical ethics committee, Faculty of Medicine, Zagazig University on 15 April 2014. Informed consent according to the criteria set by the local research ethics committee in our center was obtained in writing before surgery. 


\section{Consent for publication}

Not applicable

\section{Competing interests}

The authors declare that they have no competing interests.

Received: 23 October 2019 Accepted: 4 March 2020

Published online: 23 March 2020

\section{References}

1. Gasbarrini A, Cappuccio M, Mirabile L, Babdiera S, Terzi S, Barbanti BG, Boriani S. Spinal metastases: treatment evaluation algorithm. Eur Rev Med Pharmacol Sci. 2004;8(6):265-74.

2. Shah LM, Salzman KL. Imaging of Spinal Metastatic Disease. Int J Surg Oncol. 2011;2011:769753.

3. Bartels R..H.M.A., van der Linden Y.M., and van der Graaf W.T. Spinal extradural metastasis: review of current treatment options. CA: Cancer Journal for Clinicians. 2008; 58(4): 245-259.

4. Rose P.S and Buchowski J.M. Metastatic Disease in the Thoracic and Lumbar Spine: Evaluation and Management. J Am Acad Orthop Surg. 2011; 19(1): 37-48.

5. Yalamanchili M, Lesser GJ. Malignant spinal cord compression. Curr Treat Options Oncol. 2003;4(6):509-16.

6. Schmidt GP, Schoenberg SO, Reiser MF, Baur-Melnyk A. Whole-body MR imaging of bone marrow. European Journal of Radiology. 2005:55(1):33-40.

7. Brazilia O, Laufer I, Bilsky MH. Posterolateral approach to thoracolumbar metastatic separation surgery: a case based approach. In book spinal tumor surgery. 2019. https://doi.org/10.1007/978-3-319-98422-3-17.

8. Wise JJ, Fischgrund JS, Herkowitz HN, Montgomery D. Complication, survival rates and risk factors of surgery for metastatic disease of the spine. Spine. 1999:24:1943-51.

9. Klimo PJ, Schmidt MH. Surgical management of spinal metastases. Oncologist. 2004;9(2):188-96.

10. Fisher CG, CP DP, Ryken TC, Bilsky MH, Shaffrey Cl, Berven SH, Harrop JS, Fehlings MG, Boriani S, Chou D, Schmidt MH, Polly DW, Biagini R, Burch S, Dekutoski MB, Ganju A, Gerszten PC, Gokaslan ZL, Groff MW, Liebsch NJ, Mendel E, Okuno SH, Patel S, Rhines LD, Rose PS, Sciubba DM, Sundaresan $\mathrm{N}$, Tomita K, Varga PP, Vialle LR, Vrionis FD, Yamada Y, Fourney DR. A novel classification system for spinal instability in neoplastic disease: an evidencebased approach and expert consensus from the Spine Oncology Study Group. Spine. 2010;35(22):E1221-9.

11. Klekamp J, Samii M. Introduction of a score system for the clinical evaluation of patients with spinal processes. Acta Neurochir ( wein). 1993; 123:221-3

12. Sciubba DM, Petteys RJ, Dekutoski MB, Fisher CG, Fehlings M, Ondra SL, Rhines LD, Gokaslan ZL. Diagnosis and management of metastatic spine disease: a review. J Neurosurg Spine. 2010;13(1):94-108.

13. Greenlee RT, Murray ., Bolden S, and Wingo PA. Cancer statistics. CA Cancer J Clin 2000:50:7-33.

14. Levack P, Graham J, Collie D, Grant R, Kidd J, Kunkler I, Gibson A, Hurman D, McMillan N, Rampling R, Slider L, Statham P, Summers D. Scottishet Cord Compression Study Group. Don't wait for a sensory level-listen to the symptoms: a prospective audit of the delays in diagnosis of malignant cord compression. Clin Oncol (R Coll Radiol). 2002;14(6):472-80.

15. Sioutos PJ, Arbit E, Meshulam CF, Galicich JH. Spinal metastases from solid tumors: analysis of factors affecting survival. Cancer. 1995;76(8):1453-9.

16. Helwig-Larsen S, Johnsen A, Boesen J, Sorensen PS. Radiologic features compared to clinical findings in a prospective study of 153 patients with metastatic spinal cord compression treated by radiotherapy. Acta Neurochir (Wien). 1997;139(2):105-11.

17. Quinn JA, DeAngelis LM. Neurological emergencies in the cancer patient. Semin Oncol. 2000;27(3):311-21.

18. Boogerd W, van der Sande JJ. Diagnosis and treatment of spinal cord compression in malignant disease. Cancer treatment Rev. 1993;19:129-50.

19. Cole JS, Patchell RA. Metastatic epidural spinal cord compression. Lancet Neurol. 2008;7(5):459-66

20. Lei M, Liu Y, Tang C, Yang S, Lui S, Zhou S. Prediction of survival prognosis after surgery in patients with symptomatic metastatic spinal cord compression from non-small cell lung cancer. BMC Cancer. 2015;15:853.
21. Schiff D, O'Neill BP, Wang CH, and O'Fallon JR. Neuroimaging and treatment implications of patients with multiple epidural spinal metastases. Cancer1998; 83(8):1593-1601.

22. Rompe JD, Hopf CG, Eysel P. Outcome after palliative posterior surgery for metastatic disease of the spine--evaluation of 106 consecutive patients after decompression and stabilization with the Cotrel-Dubousset instrumentation. Arch Orthop Trauma Surg. 1999:119(7-8):394-400.

23. Chang SY, Ha JH, Seo SG, Chang B, Lee C, Kim H. Prognosis of single spinal metastatic tumors: Predictive value of the spinal stability neoplastic score system for spinal adverse events. Asian spine J. 2018;12(5):919-26.

24. Tatsui $\mathrm{H}$, Onomura T, Morishita $\mathrm{S}$, Oketa $\mathrm{M}$, and Inoue T. Survival rates of patients with metastatic spinal cancer after scintigraphic detection of abnormal radioactive accumulation. Spine1996; 21:2143-2148.

25. Jaffe HL. Tumors and Tumorous Conditions of the Bones and Joints. Cancer. 1958;12(1):629-701.

26. Brazilia O, Mclaughlin L, Lis E, Yamada Y, Bilsky M, Laufer I. Outcome analysis of surgery for symptomatic spinal metastasis in long term cancer survivors. Journal of neurosurgery spine. 2019. https://doi.org/10.3171/2019. 2SPINE181306.

27. Loblaw DA, Perry J, Chambers A, Laperriere NJ. Systematic review of the diagnosis and management of malignant extradural spinal cord compression: the Cancer Care Ontario Practice Guidelines Initiative's NeuroOncology Disease Site Group. Journal of Clinical Oncology. 2005;23:2028-37.

28. Rades D, Rudat V, Veninga T, Stalpers LJ, Basic H, Karstens JH, Hoskin PJ, Schild SE. A score predicting posttreatment ambulatory status in patients irradiated for metastatic spinal cord compression. Int J Radiat Oncol Biol Phys. 2008;72(3):905-8.

29. Bacci G, Savini R, Calderoni P, Gnudi S, Minutillo A, Picci P. Solitary plasmacytoma of the vertebral column: a report of 15 cases. Tumori. 1982; 68(3):271-5

30. Clark GM, Sledge GW, Osborne CK, Mcguire WL. Relative importance of prognostic factors for survival from first recurrence for 1000 breast cancer patients. Proc. Amer. SOC. Clin. Oncol. 1985;C-250

31. Hirabayashi H, Ebara S, Kinoshita T, Yuzawa Y, Nakamura I, Takahashi J, Kamimura M, Ohtsuka K, Takaoka K. Clinical outcome and survival after palliative surgery for spinal metastases. Cancer. 2003;97(2):476-84.

32. Spinazzé S, Caraceni A, Schrijvers D. Epidural spinal cord compression. Crit Rev Oncol Hematol. 2005;56(3):397-406.

33. Klekampe J, Sami H. Surgical results for spinal metastases. Acta Neuro chir (Wien). 1998;140:957.

34. Atanasiu JP,Badatcheff F Pidhorz L. Metastatic lesion of the cervical spine: a retrospective analysis of 20 cases. Spine (philapa 1976) 1993;18:1279.

\section{Publisher's Note}

Springer Nature remains neutral with regard to jurisdictional claims in published maps and institutional affiliations.

\section{Submit your manuscript to a SpringerOpen ${ }^{\circ}$ journal and benefit from:}

- Convenient online submission

- Rigorous peer review

- Open access: articles freely available online

High visibility within the field

- Retaining the copyright to your article

Submit your next manuscript at $>$ springeropen.com 